\title{
Incorporating design for remanufacturing in the early design stage: a design management perspective
}

\author{
Nina Boorsma ${ }^{1}$ (D) $\cdot$ Ruud Balkenende $^{1} \cdot$ Conny Bakker $^{1}$ (D) Tanya Tsui $^{2}$ (D) \\ David Peck ${ }^{2}$ iD
}

Received: 3 October 2019 / Accepted: 23 June 2020 / Published online: 11 August 2020

(C) The Author(s) 2020

\begin{abstract}
Adopting design approaches that allow products to last multiple use-cycles supports European Commission objectives to reduce greenhouse gas emissions and reduce primary material impacts. Remanufacturing is an example of an appropriate circular strategy and it can be applied in a variety of industries that are intensive materials users. However, most companies have not yet adopted design strategies facilitating remanufacturing at scale. In this paper, we explored how design management can facilitate the implementation of Design for Remanufacturing, based on a literature review and in-depth interviews. Seven companies active in business-to-business markets were interviewed about the design-related opportunities and barriers they see for remanufacturing. We found that access to technical knowledge is not a barrier, whereas integrating this knowledge into the existing design process is. We conclude that design management can contribute to the uptake of Design for Remanufacturing for the following reasons: by making the value of Design for Remanufacturing to the company at large explicit, by building bridges between internal and external stakeholders, and by embedding Design for Remanufacturing into existing processes by means of Key Performance Indicators (KPIs) and roadmaps.
\end{abstract}

Keywords Design for Remanufacturing · Design management · Implementation · Circular product design $\cdot$ Product development $\cdot$ Multiple use-cycles $\cdot$ Closed loop supply chains

\section{Introduction}

For decades, the practice of remanufacturing has been used as a tool to create economic benefits from previously used products. From an environmental sustainability perspective, extending the life of a product via remanufacturing is a promising approach to reduce

Nina Boorsma

N.E.Boorsma@tudelft.nl

Extended author information available on the last page of the article 
pollution, in particular $\mathrm{CO}_{2}$ emissions, and our dependence on primary (geologically sourced) material use.

The closed loop, product life extension, lower impact, approach fits within the frame of the circular economy. In the EU, Circular Economy (CE) is a relatively new policy concept that came into the spotlight following the European Commission's 2015 CE Action Plan [22].

Remanufacturing is an example of a strategy which supports CE. It is applied in a range of intensive material using industries. Technical solutions for remanufacturing are extensively discussed in the literature and are centred around product design to facilitate the remanufacturing process, which includes disassembly, cleaning, testing, and reassembly [26, 28, 31, 46]. The emphasis is on optimising part re-use by minimising the possibility of parts being damaged during the process. This helps in maintaining high product quality at a low cost, and reducing production time. To tap into the full potential of these technical solutions, integration within the new product development process is crucial, yet uncommon in practice [46].

Strategic design solutions may advance this integration, however their development is much less reported in the literature [29, 37]. Strategic design takes place during the early phase of product development and is concerned with concept development based on, for example, market analysis, consumer behaviour, product portfolio management, and the available innovation capacity. The body of literature on topics like market analysis and consumer behaviour is growing [25, 49], however discussions are rarely linked back to early stage design activities.

In this study, therefore, we investigated the opportunities and barriers to implementing Design for Remanufacturing in early stage product development. We aimed to build a better understanding of these early stage dynamics by taking a design management view. Design management provides a structural approach to exploring the value created through design by taking different perspectives like a customer perspective and learning perspective [7]. This allowed us to explore the full potential Design for Remanufacturing can have for the entire company.

In the background section, we introduce the concept of design management in more depth and present the corresponding roles found in the literature with regard to remanufacturing. In the methods section, we explain how we collected data through in-depth interviews. Lastly, we analyse the results and finalise with a discussion and the overall conclusion.

\section{Background}

\section{Framework}

The objective of giving products multiple use-cycles through remanufacturing is to create benefits for the target market, the environment, and for profitability [3, 21, 27, 36, 55]. The better a product's design is adjusted to serve multiple use-cycles, the greater these benefits will be $[26,28,50,52,54]$. In this paper, we use the following definition of remanufacturing, as described by the International Resource Panel [32]:

"[Remanufacturing] refers to a standardized industrial process that takes place within industrial or factory settings, in which cores are restored to original as-new condition and performance, or better. The remanufacturing process is in line with specific technical specifications, including engineering, quality, and testing standards, and typically yields fully warranted products. Firms that provide remanufacturing 
services to restore used goods to original working condition are considered producers of remanufactured goods."

Design for Remanufacturing literature is primarily concerned with finding the optimal alignment between product properties and the remanufacturing production process [26, 28, 46, 55]. In their paper, Prendeville and Bocken [51] highlight the importance of strategic design as a wider frame to add to the technical design solutions. Strategic design takes place in the early stage of product development and is expected to lay the foundation for a more integrated remanufacturing design strategy. Formulating an innovation direction requires expertise and input from different disciplines, including business development, marketing, manufacturing, and product development. In line with this, Lindkvist Haziri and Sundin [39] also explored the opportunities to include insights from the remanufacturing department in these early stages of product development. In their study, they assessed both the current, and ideal, level of information exchange at a manufacturer of electro-mechanical machines. To achieve this, they used design tools like visualisation techniques. In the following step of the study, they identified concrete actions to implement the ideal scenario. One of the important factors they mention in building up a relationship between departments is to sensitise employees to each other's work. One of their proposed solutions was to give designers first-hand experience by having them visit the remanufacturing production line.

The importance of strategic design for remanufacturing was already recognized in studies from the 70s, where, for example, Lund and Denney [42] reported the success of effects of customer perception, product planning, and innovation management. The authors highlight that customers should be wellinformed about benefits like cost savings, and that product parts should, where possible, be standardized across different models alongside product innovation. Calabretta and Gemser [10] define strategic design as the following: to "co-determine strategy formulation and implementation toward innovative outcomes that benefit people and organisations alike". This definition shows that besides using design to implement a strategy, it can also be of use to formulate a strategy.

To get an understanding of the full potential strategic design can have within an organisation, we have turned to the field of design management. This field revolves around more generic values of design: value creation, problem solving, skill improvement, and design as leadership (to reach company goals) [13]. Design management makes use of design competencies to connect market needs with company goals in creating products and/ or services. This can, for instance, be directed at improving product performance or durability, or be applied to the integration of new design requirements, or to creative thinking to find new business opportunities. Other roles associated with design management are creating competitive advantage, improving customer perception, and increasing market share [6]. Its value becomes particularly evident in multidisciplinary environments involving complex problems [14].

Borja de Mozota [7] created a balanced score card for design managers. She formulated four capacities for design: design as differentiator, design as integrator, design as transformer, and design as good business. Design as differentiator takes a customer perspective and focuses on design's abilities to be distinctive from competitors and to be easy to recognize for customers. Design as integrator takes a process perspective, and focuses on design's abilities to function as an innovator of the product development process, by, for example, implementing new tools or methods. Design as a transformer takes a learning perspective. It is about the ability to assist a company in adapting to change, in, for example, finding new business opportunities. Lastly, design as good business takes a financial perspective and focuses on design's ability to increase financial gains and actualise sustainable growth for the business by, for example, increasing the market share. 
Using Borja de Mozota's design capacities and perspectives, we developed a framework for design management roles for remanufacturing (Table 1). For each of the four design capacities and perspectives (i.e. Design as Differentiator/ Customer perspective, etc.), the remanufacturing literature was reviewed to identify opportunities and barriers for design management. After grouping the opportunities and barriers, sub-categories for each perspective emerged. For example, based on the literature, the Customer Perspective was further subdivided into market assessment, customer acceptance, and customer relationships. For each of these sub-categories, we then assigned a number of design management roles. We would for instance find in the literature that a clear definition of suitable markets for remanufactured products is important, but that companies often do not prioritise the activities of defining markets and collecting market insights for remanufactured products [24, 58]. Based on this finding, we concluded that a role for design management would be to 'identify customer needs that can be met by offering remanufactured products'. We have applied this approach for all the roles included in Table 1. In the following section we describe our approach in more detail. The findings of the literature review can be found in Table 4 in Appendix 1.

\section{Opportunities and barriers to implementing Design for Remanufacturing}

Design management roles were identified based on opportunities and barriers to implementing Design for Remanufacturing; these are discussed below for each of the four perspectives. The design management roles derived from these opportunities and barriers are listed in Table 1.

\section{Design as differentiator - the customer perspective}

This perspective discusses the connection of the company to its market. Understanding market dynamics and customer needs allows a company to develop products and/ or services that fit its market. When remanufacturing is concerned, efforts to define markets and collect market insights are usually not prioritised within companies [25, 59]. A growing market demand for remanufactured products is expected to positively influence the marketing teams' commitment to perform such studies $[17,29]$. However, the risk of cannibalizing new sales is often highlighted as a drawback in promoting remanufactured goods [40]. For market assessment, possible roles for design management therefore are identifying target markets and identifying customer needs that can be met through remanufacturing.

From the customer's point of view, the interest in remanufactured products is affected by the lack of information about product history, the remanufacturing process, and/ or product quality $[1,17,26,30,58]$. Financial risks most prominently influence the purchasing intention $[42,48,53,58]$. Improved information transparency and certification or quality labels are expected to improve the quality perception $[1,30,35,47,48]$.

Lastly, customer cooperation can influence the success of remanufacturing (e.g. proper use of products or timely product returns) [42]. The customer relationship can be improved by instructing customers about the desired use [16]. This can for example translate into the design management role of engaging customers and stakeholders in returning products timely.

\section{Design as integrator - the process perspective}

The process perspective focuses on all actions required to get from a business idea to market introduction. It involves the actual product development and the design competencies needed to fulfil the tasks. To develop remanufacturable products, the development department needs to receive 
Table 1 Design management roles for remanufacturing (based on literature)

Design as differentiator (Customer perspective)

Sub-categories

Market assessment

Analysing a market for a product/ service offer to make predictions about the market size and ideal product price [38]

\section{Customer acceptance}

Customer's agreement that a product and/ or service fits in the category that meets a customer's standard or needs [2]

\section{Customer relationships}

The behavioural patterns, and feelings linked with those patterns, a company and its customer(s) have developed over time in relation to the company offer [15]

Design as integrator (Process perspective)

\section{Sub-categories}

Information management

The company's internal approach to collect, organise, store and provide information [33]

\section{Collaboration}

The combined efforts of two or more stakeholders to complete a task or assignment [11]

Organisational support

Work conditions of an organisation such as behaviours and routines that allow an action to take place [57]

\section{Commitment}

The willingness of a person to dedicate time and effort to a particular task in order to complete it [12]

Integration with existing processes

The process of introducing new knowledge into a previously established routine to accomplish new or adjusted goals [34]
Design management roles

- Identify customer needs that can be met by offering remanufactured products $[25,59]$

- Identify the added value of remanufacturing to the marketing department [17, 29]

- Identify and document product specific information that could support the purchasing process of customers [1, 17, 30]

- Increase awareness and trust by developing a marketing and branding strategy for remanufactured products [30, 35]

- Communicate the need for certifications for remanufactured products to trade unions $[35,47,48]$

- Instruct customers about the desired return procedure $[16,42]$

- Engage customers and stakeholders in the timely return of products $[16,42]$

Design management roles

- Specify and communicate product information required by both the remanufacturing department and the product development department $[29,39$, $40,55]$

- Identify opportunities to create value in collaboration with supply chain partners [28, 29, 53]

- Organise interdisciplinary workshops to co-create and exchange experiences, preferably at a location where the participants can gain first-hand experience [53]

- Promote the development of routines and channels for internal collaboration and information exchange [40, 53]

- Involve management in developing and communicating a clear vision on remanufacturing $[29,40]$

- Identify departments and the employees that need to be involved in the tasks [29, 39]

- Identify potentially conflicting product requirements (in relation to remanufacturing) at an early stage [28, 53]

- Integrate remanufacturing knowledge into existing methods and tools, throughout the whole product development process [24, 28, 61] 
Table 1 (continued)

Design as transformer (Learning perspective)

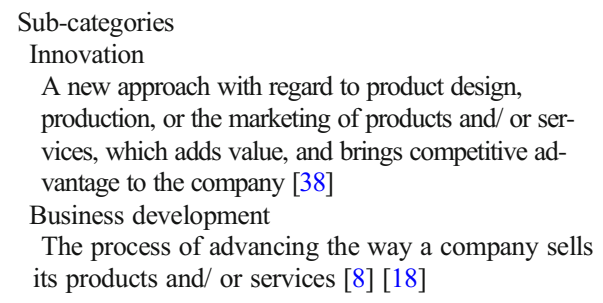

Design as good business (Financial perspective)
Design management roles

- Identify target parts and components for remanufacturing at an early stage $[42,49]$

- Identify the business value of having short lead times for product availability [45, 49]

- Explore the opportunities to adopt access or performance business models $[35,52,56]$
Sub-categories

Financial drivers

Incentives related to finance that influence the decision-making process to advance business growth [19, 23]

Market share

The percentage of customers in a particular market accommodated by a company [44]

\author{
Design management roles \\ - Explore the possibility to use remanufacturing for \\ quality and brand management $[41,45,53]$
}

- Assess the risk of cannibalizing new sales by offering remanufactured products $[35,40,53]$

input from the remanufacturing department. An important factor is that the required information should be carefully specified [40]. In turn, the remanufacturing department requires detailed product information from the product development, manufacturing and servicing, to produce high quality output $[29,55]$. Currently, channels for information exchange are often non-existant or rely on informal exchanges $[39,53]$.

What could help improve these exchanges is setting up interdepartmental collaborations. Organising workshops, for example, is a way of bringing different stakeholders together. These workshops can also take place with external stakeholders, for example, with part suppliers. These collaborations can help in taking a lifecycle perspective during product development [29, 53]. It is important to carefully coordinate these collaborations [29]. Coordinating these workshops has been identified as a role for design management.

In support of collaborations, it helps to have a clear strategy formulated by top management and that this is communicated throughout the company [29]. This can also help spread awareness and knowledge of remanufacturing, which tends to be concentrated at the remanufacturing department [39].

In addition to acquiring information, people's task-commitment is expected to be at least as important [29]. Companies with a clear overall vision, and task division, motivate their employees to take action [29]. This motivation can be enhanced by giving employees first-hand experience of a subject $[29,39]$. This can be achieved by, for example, inviting them to the production line and scheduling regular follow ups [29, 39]. From the employee's point of view, a lack of trust in product quality and the absence of leadership have negative effects on motivation [29]. A role for design management in getting employees committed is identifying and assigning relevant tasks.

To ensure improved integration of remanufacturing guidelines into the existing process, the literature notes the importance of early stage design [24, 29, 35, 53, 61]. Early stage involvement can also assist in signalling and solving the unwanted effects of adding new requirements (e.g. increased environmental impact) $[28,51,53]$. The use of design tools can also be of value; 
familiarity with, and the complexity and accuracy of these tools is essential for a seamless integration [28]. Roles for design management therefore are the early identification of potentially conflicting product requirements and improving the compatibility of new design tools.

\section{Design as transformer - the learning perspective}

The learning perspective focuses on finding new ways to design, manufacture, or market products. In this context, it is important to design products that are suitable for the remanufacturing process. Remanufacturing can also be used as a tool to innovate. For example, from a marketing point of view, since remanufacturing allows for shortened timeto-market lead times compared to that of new products, it can be used as a tool to react to a sudden market demand [45, 49].

Another important aspect is the return flow of products, as input for the remanufacturing process. One way to support this is through product development: by identifying and standardising (target) parts and components to create more homogeneous volume [42]. Another way is to adopt different business models. A shift from sales models to access or performance business models, for example, can increase the return flow of products $[4,35,55,56]$. To support such a shift, setting up new supply chain collaborations may be valuable $[35,53]$. A role for design management is, therefore, to explore the opportunities for adopting access or performance models.

\section{Design as good business - the financial perspective}

The financial perspective is the fourth perspective; it's value is related to the way a company optimises its profit from remanufacturing. Improving product design can help to increase profit margins and ecological benefits [9, 29, 41, 53]. The most promising scenarios to initiate remanufacturing are those where costs for initial production are high and costs for remanufacturing are low [17]. The required labour, and more frequent servicing, however, can add significantly to the costs of remanufacturing [51].

Competing remanufacturers are the main drivers for Original Equipment Manufacturers (OEMs) to start up remanufacturing $[29,48]$. OEM remanufacturing can prevent third party remanufacturers from entering the market [53]. Yet, companies producing low-budget or counterfeit products can also be a threat $[35,53]$. At the same time, OEMs perceive cannibalisation of their own new product sales to be a risk [35]. A role for design management is to explore the possibility to use remanufacturing as a tool for quality and brand management.

\section{Methodology}

To set the starting point for this study, we reviewed the literature for barriers and opportunities for design management for remanufacturing. A combination of the search terms 'remanufacturing', 'product design' and 'management' was used to find articles in the Scopus search engine; this yielded 102 documents. We narrowed this number down by selecting articles focussed on non-engineering barriers and opportunities affecting the design process, from a consumer, process, learning, and financial perspective. We based this on the titles and abstracts, and by looking for keywords 
such as: integration, implementation, acceptance, knowledge, demand, needs, value, awareness, risks, costs and coordination. The resulting papers were read in more detail and additional papers were found through snowballing. In the end, 26 papers were selected for the literature overview (Appendix 1), of which 22 formed the basis for the design management roles for remanufacturing presented in Table 1, column 2 . This table was structured according to the four capacities of design described by Borja de Mozota [7]. The sub-categories that emerged by grouping the input from literature were defined using additional references, see Table 1, column 1 .

After developing the framework, we conducted in-depth interviews to further explore the possible roles for design management in the implementation of Design for Remanufacturing. Figure 1 shows the research process.

Seven companies operating in business-to-business markets were selected for inclusion based on their product properties, their level of influence on the product design, and their interest in (setting up) remanufacturing activities. The first criterion was that the company's product properties had to have the potential for remanufacturing. Examples are durability, the possibility for long term part standardisation, and the use of a stable technology [43]. The second criterion was that the companies could influence decisions made in the product development process; there had to be a link with the product development department. The last criterion was the level of interest in recovery activities; a basic interest in setting up remanufacturing was required. The final selection included four OEMs, two OEMs with recovery activities in place, and one third party remanufacturer. A summary of the case details can be found in Table 2 and the company descriptions can be found in Appendix 2.

Interviews with these companies were conducted following the structure for shorter interviews described by Yin [60]. They were semi-structured and lasted approximately one hour each. The interview protocol led discussions around opportunities and barriers to remanufacture products from a product design perspective, and can be found in Appendix 3. The interview recordings were then transcribed.

The data for the company producing window shades (A4) was collected in a four-hour workshop, followed up by conversations with the company. This workshop was set up using a protocol in the form of worksheets and structure documents from an EU project [5]. Elements discussed were the opportunities for remanufacturing the product in relation to market potential, product and production, and the remanufacturing process.

Data analysis was performed using the framework of design management roles for remanufacturing presented in Table 1 . The researcher carefully went through the transcriptions in order to develop themes that reflected the respondents' meanings. These were related to opportunities and barriers for design management and addressed market issues, customer perspectives, product design issues, and finances; the findings are summarized in Table 3. Themes found for design as a differentiator, for example, were: market assessment, customer acceptance and customer relationship. In the following step, we compared these opportunities and barriers to the design roles in Table 1. This led to the identification of a number of new roles for design management; these are described in the discussion.

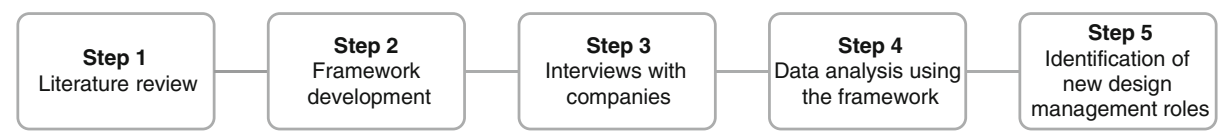

Fig. 1 Research process steps 


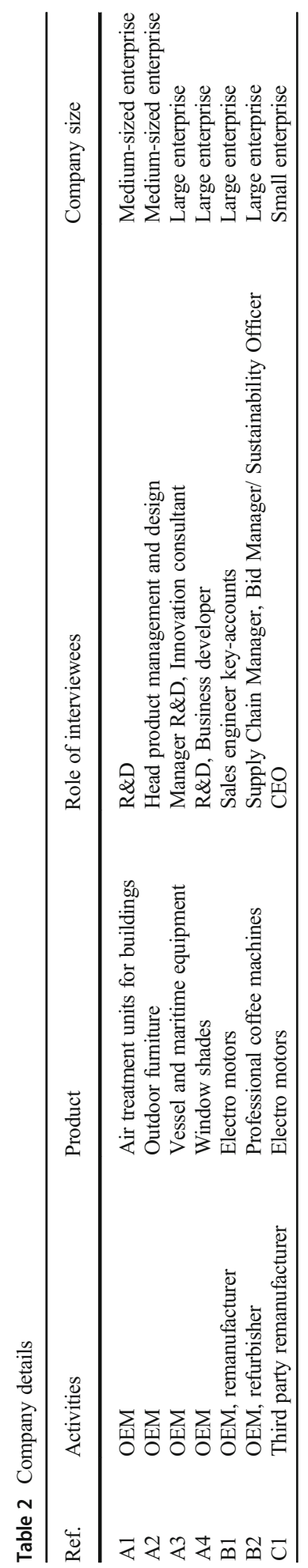


Table 3 Design management roles for remanufacturing (based on interviews)

Design as differentiator (Customer perspective)

Opportunities and barriers per sub-category

Market assessment

- The market is not actively seeking remanufacturing. (A2, A3, A4, B)

- Customers are often unaware of the possibilities to have their products remanufactured. (A1, A3, A4, B1)

- Customers are unaware of the possibility to use remanufacturing as a tool for spare part supply.

(A1, B2, C1)

- Customers are unaware of the additional advantages of remanufacturing, for example, the possibilities to make modifications (e.g. improving energy efficiency). (A1, A3, C1)

- Product take-back for parts harvesting or recycling is not considered valuable. (B1)

- For customers, economic benefits form the main driver to remanufacture, resource savings, is not considered a priority. (A2, A3, A4, B1, C1)

- Companies are unaware that initial time and costs to set up remanufacturing operations can be fairly low. (C1)

Customer acceptance

- Economic benefits are not prioritized above the perceived risk. (A1)

- Customers' decision-making process is based on both ratio and emotions. (A4, B1, C1)

- Circular offers are new to certain markets, customers need time and resources to explore the benefits of remanufacturing. (A1, A2, A4)

- The conservative nature of certain markets prevents acceptance of new types of offers. (A1, A2, A3, A4, B2)

- Customers settle for lower grade materials to get short term price benefits. (A2, C1)

- The lack of confidence in a product's suitability for - " remanufacturing is a major barrier to starting up remanufacturing (with a contractor). (C1)

- There is no remanufacturing certification to convince customers of product quality. (A2)

Customer relationship

- Certain industries (e.g. the building industry) have no existing direct communication channels with end-customers. (A1, A2, A4)

- The dynamic and complex nature of the supply chain leaves companies with little to no influence after initial sales. (A1, A4)

Design as integrator (Process perspective)

Opportunities and barriers per sub-category Information management

- Product data is collected for providing services, but - Specify and communicate product information not to make product design improvements. (A1, A2)
Design management roles

- Increase awareness and trust by developing a marketing and branding strategy for remanufactured products

-

-

-

- Identify and document product specific information that could support the customer purchasing process - "

- 6

- The need for certifications for remanufactured products to trade unions

- No role assigned

- No role assigned

Design management roles required by product development department 
Table 3 (continued)

- Collecting product use-data is essential to improving remanufacturing quality. (B4, B1)

- There is no existing feedback loop with the development department. (B1)

Collaboration

- Organising workshops is an effective way to get people acquainted with new initiatives, however it does not ensure continuity. (A3)

- Product developers do not feel they have the power to influence other departments like business development. (A2)

- A lack of effective communication between the procurement department and product development department can cause a significant barrier. (C1)

- Procurers have a strong focus on short-term financial gains. (C1)

Organisational support

- Companies have limited Full-Time Equivalents (FTEs) available dedicated to (design for) remanufacturing. (B2)

- Companies fail to adopt remanufacturing in their strategic goals. (A1, A3, A4, C1)

- Commitment to change is needed to transform linear to circular organisational structures, as they are absolute opposites. (A2, A3, B2, C1)

Commitment

- Engineers do not embrace sustainable or circular design because of the preconception that it is more expensive to produce. (A3)

- A clear vision, personal commitment and perseverance are required to initiate remanufacturing activities and to get colleagues on board. (A3, C1)

Integration with existing processes

- For it to be effective, Design for Remanufacturing should be put on the agenda in the early stages of the design process. (A3)

- Most actions towards implementing Design for Remanufacturing originate from bottom-up initiatives. (A3, A4, B2)

- Concrete and practical actions to for implementation are missing. (A3)

- Design for Remanufacturing is expected to be a trade-off with initial product quality. (B1)

- Careful selection of products to remanufacture can save time and money. (B1, C1)

\section{Design as transformer (Learning perspective)}

Opportunities and barriers per sub-category Innovation

- Rapidly changing product portfolios form a barrier - Identify target parts and components at an early stage to adopt (design for) remanufacturing. (B1, B2)
- Specify and communicate product information required by the remanufacturing department

- Promote the development of routines and channels for internal collaboration and information exchange

- Organise interdisciplinary workshops to co-create and exchange experiences, preferably at a location where the participants can gain first-hand experience

- Promote the development of routines and channels for internal collaboration and information exchange

- " $\quad$ "

- Identify departments and the employees that need to be involved in the tasks

- Identify departments and the employees that need to be involved in the tasks

- Involve management in developing and communicating a clear vision on remanufacturing - "

- Involve management in developing and communicating a clear vision on remanufacturing

- Integrate remanufacturing knowledge into existing methods and tools, throughout the whole product development process

- Identify departments and the employees that need to be involved in the tasks

- Identify potentially conflicting product requirements (in relation to remanufacturing) at an early stage

- Identify target parts and components at an early stage
Design management roles 
Table 3 (continued)

- Uncertainty about future market and technological - No role assigned developments makes designing for the long term risky. (A3, A4)

- Designing products for remanufacturing can assist - No role assigned in solving production errors of new products by allowing product modifications. (B1)

Business development

- Only few companies are aware of the benefit of controlling their brand image through product takeback. (A1, B2)

- New partnerships are necessary to shift to access-based models. (A2, B1)

- Supply chain collaboration is key to come up with truly circular concepts. (A2, A3, A4, B1)

- The required business processes for remanufacturing - No role assigned are considered to be too complex. (C1)

- Access models are difficult to set up when the - No role assigned customers are manufacturers. (B1)

- Being highly dependent on suppliers is likely to - No role assigned become riskier over time. (A2, B2, C1)

- For our company to explore a new business opportunity, a business case is required. For remanufacturing, a feasible business case is required. (A3)

- Feasibility studies for new product development tend to be based on direct costs and profits only. (B2)

- It can be hard to attain long term competitive advantage by use of labels, standards and certification. (A2)

- Setting up the remanufacturing operation is not - Explore the possibility to use remanufacturing for quality and brand management

- Identify opportunities to create value in collaboration with supply chain partners

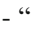

- No role assigned

- No role assigned

- No role assigned the most difficult part; setting up the business and logistics around it is most difficult. (A4, C1)

Design as good business (Financial perspective)

Opportunities and barriers per sub-category

Financial drivers

- Financial decision makers are not necessarily product experts, but have great power. (A1, A4)

Design management roles

- Company reward systems in sales departments are - No role assigned attuned to new product sales. (A3)

- Remanufacturing is generally labour intensive. (A4, - No role assigned B2, C1)

Market share

- The fear of market cannibalization is a barrier to remanufacturing. (A4)

- Assess risk of cannibalizing new sales by offering remanufactured products

External drivers

- Companies benefitting from economies of scales of - No role assigned mass-produced new products form strong competition to remanufacturing. (B1)

- Certain markets have such a strong competitive - No role assigned nature that parties with radical new ideas are unlikely to survive. (B2)

- Once a product is installed in the public domain, it - No role assigned is impossible to retain ownership. (A2) 
Table 3 (continued)

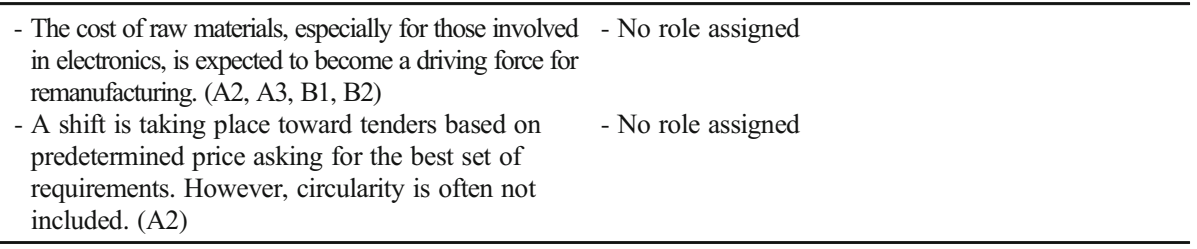

\section{Results}

In this section, we describe the findings from the interviews for each of the four design capacities. The list of opportunities and barriers is presented in Table 3, column 1. The details for the case references can be found in the methods section in Table 2. In the discussion section, we reflect on how the opportunities and barriers link to the earlier-identified design management roles (Table 3, column 2).

When analysing the interviews, we added the new sub-category called external drivers to the capacity of design as good business (the financial perspective). External drivers are defined as incentives out of the company's control that influence the company's way of doing business [19, 20].

For each of the four capacities we were able to identify opportunities or barriers that were not mentioned in the literature reviewed for this paper. We will discuss these opportunities and barriers in more detail, starting with the sub-category customer relationship. The barriers found here are the result of operating in highly complex supply chains. Due to this complexity, companies may not have existing channels to communicate with their (end) customer and therefore experience difficulties when initiating circular models. To illustrate this, an interviewee from company A1 describes their customer relationship as follows:

"We do not deliver our products to the end user or the building investor, but to the installer. Once the system is installed, the end user is out of our sight. This is where we try to make a connection, to stay in the picture. Only then can we start offering circularity."

In the next sub-category, innovation, the interviewees from companies A3 and A4 mentioned the risk of designing products for the long term because of the difficulty of assessing future market needs and uncertainties regarding technological developments. The interviewee from company A3 shared the following:

"Our assets last for many decades, but at one point they become outdated, written off, or too expensive to maintain. How can we deal with this? One thing to consider is the difficulty of looking into the future. Most people say: 'I don't believe in [circular design]. You don't know anything about what's going to happen after five years.' And the challenge is that a lot of our products are custom built, so how do you approach remanufacturing when every part is slightly different to the other? This is a big challenge."

In the business development sub-category, many barriers have to do with the complexity of setting up circular business models. Companies A3 and B2 point out the misalignment of exploring circular business opportunities with the existing way companies develop new business cases. The existing process is strongly driven by direct costs and profits, and leaves very little room for exploration. In addition, companies A2, B2 and $\mathrm{C} 1$ sense that it is important to collaborate with supply chain partners, yet they experience dependence as a risk for the longer term. The interviewee from company $\mathrm{C} 1$ noted the following: 
"Many potential customers were initially very interested in remanufacturing. But once they headed back to their company, they experienced a lot of resistance; it was not a priority and it was expected to be too complex. Which it is. Any business expert knows that a linear process is simpler than a circular process. But, in the end, you will earn more money with it."

A quote from the interviewee from company $\mathrm{C} 1$ illustrates the need for collaboration with supply chain partners to make remanufacturing feasible:

"We were in the process of remanufacturing a very expensive pump, when we realised that replacing the worn-out component would be incredibly expensive. This was due to the price the supplier charges for spare parts. Buying a new pump would almost cost the same."

Another example, with regard to the dependency of suppliers, was given by the company B2 interviewee:

"The design of our machines changes every five years. If we extend the product lifetime even further, there is a big chance we will run out of spare parts. The supplier simply no longer produces those parts. By refurbishing a second or third time, we would risk not being able to service the machines in field properly. That is why we only refurbish our machines once."

The sub-categories financial drivers and external drivers also yielded several new barriers. While the external barriers mentioned are difficult to influence through design management, the financial barriers can be influenced. One of the barriers relates to the company reward system for product sales. The company A3 interviewee explained the following:

"[In selling remanufacturing products] the main obstacle, internally, would be the reward-system. [The way it is organised now, sales people get paid as a percentage of the new-build products. When you stop selling new-build, how should the reward structure for sales be organised so that that they will accept and work with it? The reward-system has to change."

\section{Discussion}

In this section, we compare the opportunities and barriers found in the interviews with the earlieridentified design management roles for remanufacturing. Most of these barriers and opportunities have been addressed in similar forms in previous studies in literature and can therefore be linked to design management roles identified in the background section (Table 3, column 2).

A number of opportunities and barriers were linked to the same design management roles because they share an underlying cause, for example, for the opportunities and barriers related to customer awareness under the sub-category market assessment. The role linked to these opportunities and barriers is to 'increase awareness and trust by developing a marketing and branding strategy for remanufactured products' and covers all of the barriers in this subcategory.

Several barriers from the interviews did not show clear links with the reviewed literature. For these, we formulated additional roles for design management based on insights from the 
cases and by reflecting on the literature review in the background section. We discuss these additional roles in more detail in this section.

Firstly, for design as a differentiator, the new role is to 'Identify what new channels are suitable to start up communication with customers in complex supply chains'. This role addresses the difficulty for companies in complex supply chains to communicate with their (end-) customers. The importance of communication with customers, as well as the type of information to be communicated, have been thoroughly discussed in the literature [1, 30, 35, 47, 48]. In industries with complex supply chains, however, there are often no existing communication paths with these customers; therefore these need to be developed (A1, A2, A4).

One new role was identified for the process perspective: 'Identify the added value of remanufacturing to the manufacturing department'. The importance of the exchange of product/ production information between the manufacturing department and remanufacturing department is addressed in the literature $[29,40,55]$. In our study, we found that remanufacturing can also add value in other ways, for example by resolving production errors (B1).

For the learning perspective, we found one additional role: 'Compile technological roadmaps to make estimations of the duration certain technologies will be used'. To include remanufacturing in early stages of the product development process has proven to be important, for example, when identifying which component can be standardized [24, 28, 35, 53, 61]. In line with this, and to support portfolio management, drafting an early stage technology roadmap is essential for identifying design opportunities (B1, B2).

For the financial perspective, we added two new roles for design management. The first of these is to 'Identify the non-financial benefits of remanufacturing'. While the literature discusses the costs and profits, the non-financial benefits are also likely to have a valuable impact $[9,17,29,41,53]$. A shift towards a value-based view in, for example, feasibility studies, by including aspects like brand management, parts harvesting, and the possibility to reduce time-to-market, will demonstrate the full potential of remanufacturing (A1, B1, B2).

The second role is to 'Identify existing KPIs which are directly or indirectly unsupportive of remanufacturing, and formulate new KPIs where possible'. The topic of KPIs is not extensively discussed in the literature due to the fact that remanufacturing is often not yet embedded in the company. One of the case study companies addressed this topic by noting that company reward systems in sales departments are attuned to new product sales, while no reward system is in place for the sales of remanufactured products (A3).

For this study we interviewed seven companies in addition to the literature review. Even though this number is limited, it resulted in the formulation of several new roles. This implies that either 1) the topic requires a more extensive literature review to cover the remaining roles, or 2) there is much more to be expected from design (management); it is an overlooked capacity that might be instrumental in making remanufacturing more successful.

\section{Conclusion}

The use of a design management approach leads to a good understanding of the importance of strategic design for remanufacturing and it leads to formulating concrete actions. As a starting point, we were able to formulate a number of design management roles based on the literature review. This was reviewed using a design management framework based on four capacities of design: design as differentiator, design as integrator, design as transformer, and design as good business. The framework was further developed by adding sub-categories to these capacities, based on grouping the 
opportunities and barriers found in remanufacturing literature. After conducting in-depth interviews with seven different companies, we defined several additional roles for design management.

Design for Remanufacturing has been thoroughly discussed in literature in recent decades. Its implementation in practice, however, has not followed at the same pace. The (early) integration of the knowledge into existing company processes is considered important. Current literature has revealed numerous points for improving the uptake of this knowledge in the early design stage. Our study contributes by initiating an exploration for concrete design management roles, as a next step in finding a structured approach for implementing Design for Remanufacturing.

As a result, we found that the roles for design management can contribute in three ways. Firstly, they make explicit the added value of Design for Remanufacturing for an organisation. Additionally, the roles aid in building bridges amongst both internal and external stakeholders. And finally, they contribute to embedding Design for Remanufacturing into existing processes by means of KPIs and roadmaps.

The exploratory work in this paper yielded a detailed list of concrete design management roles for remanufacturing. To get insights in the added value of these roles in practice, further research is needed. In-depth studies with companies have the potential to provide a more detailed description of the added value of these roles. They can also help in further detailing and finetuning, as well as increasing our understanding of their effect on information exchange and collaboration amongst stakeholders. Lastly, in-depth case studies may reveal opportunities or knowledge gaps for further development of (early stage) design tools to aid OEMs in the development of remanufacturable products.

Acknowledgements This paper was funded through EU-funded H2020 project 'Resource-Efficient Circular Product Service Systems' (ReCiPSS), under grant agreement number 776577-2. The results were collected in EU-funded EIT KIC Raw Materials projects, called: 'Remanufacturing Pathways' (RemanPath), under grant agreement number 17087, and Catalyse Remanufacturing through Design Bootcamp (CARED), under grant agreement number 18024 .

\section{Appendix 1}

Table 4 Literature review summary: Opportunities and barriers to implement Design for Remanufacturing

Design as differentiator (Customer perspective)

Opportunities and barriers

Market assessment

- There is a lack of knowledge about the effect of market dynamics on the success of remanufacturing [25, 59].

- Recognizing customer demand for remanufactured products as a customer need should trigger implementation of Design for Remanufacturing into the product development process [29].

- Remanufactured products are less likely to thrive in a market where demand is concentrated at the lower end, mainly due to an expected strong competition in this lower segment [17].

- Market demand for remanufactured products results in support from the marketing department [29].

- The marketing department may be guarded about promoting remanufacturing offers, because of the risk of cannibalizing new sales [40].

Customer acceptance

- Remanufactured products are perceived to have a lower value than new products [17].

- Customer perception on product quality is a significant determinant for demand for remanufactured products $[17,26,35]$. 
Table 4 (continued)

- The perceived quality of remanufactured products is strongly related to the expected total costs of ownership, product performance, safety, and serviceability [1, 30, 58].

- The perceived financial risk was found to be the most prominent factor influencing the purchasing intention of remanufactured products, where, besides the purchasing price, future maintenance and servicing costs are considered as well [42, 48, 58].

- Quality perception can be improved by introducing a reference, like certification or a quality label, to inform customers when buying remanufactured products [1, 35, 47, 48].

- Transparency about the origin and production process of a remanufacturing product towards the customer significantly influences customer acceptance $[30,35]$.

- Customers' value perception of new products decreases when they are informed about the environmental benefits of a remanufactured equivalent [48].

- Customers' willingness to pay is higher for new products than for remanufactured products, especially when information about the recovery process, product quality, and/ or environmental impact is not provided [30, 48].

Customer relationship

- The success of remanufacturing is heavily dependent on customer cooperation in remanufacturing business models [42].

- Product durability is related to customer behaviour during use and can be affected by instructing customers [42].

- Not all remanufacturers are confident about their customers' willingness to cooperate (e.g. in returning products, taking good care of products) [16].

- A strategy for remanufacturers to build good customers relationships is to lead by example by initiating the behaviour they would like their customers to mirror [16].

Design as integrator

(Process perspective)

Opportunities and barriers

Information management

- The channels for information feedback from the remanufacturing department to the development department are missing [40].

- The remanufacturing department should have access to product information [55].

- The remanufacturing department can benefit from formal channels to receive information from service technicians [29].

- Disintegration of Design for Remanufacturing can result from a disconnect between the sales organisation and the production facilities of a company [39].

- In-depth knowledge about remanufacturing is often restricted to the remanufacturing department [39].

- It should be clearly defined what exact remanufacturing information the development department can benefit from [40].

- Informal routines and exchanges (e.g. experience and social relations) store important procedural knowledge and information [53].

Collaboration

- Collaboration between the remanufacturing department and product development department is likely to require improved levels of coordination [29].

- OEMs do not develop all of their parts in house [29].

- There is a lack of knowledge about the product information exchange between OEM and a contract remanufacturer to improve business results [28].

- Interdisciplinary and/ or stakeholder workshops are needed to find innovative solutions for remanufacturing [53].

Organisational support

- (Top) management is in charge of decision making on Design for Remanufacturing implementation [29].

- The company definition and objective of remanufacturing should be clear throughout the whole company [29].

- Awareness of, and knowledge about, remanufacturing is generally not spread throughout the organisation, but concentrated at the remanufacturing department [40].

Commitment

- Design engineers can be sensitized to the implementation of Design for Remanufacturing by giving them a first-hand experience on the remanufacturing shop-floor [39]. 
Table 4 (continued)

- Motivation for design engineers to use Design for Remanufacturing guidelines is dependent on individual values, but is also strongly dependent on company incentives [29].

- Motivation for design engineers to implement Design for Remanufacturing is expected to be more critical than having knowledge about Design for Remanufacturing [29].

- A lack of trust in remanufactured process and product quality can lower the motivation of design engineers [29].

- Frequent touchpoints with the remanufacturing department motivate design engineers to prioritise Design for Remanufacturing [29].

- It is not clear who should be in charge of the implementation of implementing Design for Remanufacturing [29].

Integration with existing processes

- Trade-offs between Design for Remanufacturing and further design requirements should be addressed [28].

- Design for Remanufacturing should be considered in an integrated way with other product requirements to avoid unwanted effects like an increase in cost or increased environmental impacts [28, 51, 53].

- Lifecycle thinking improve the uptake of Design for Remanufacturing [28].

- The use of existing tools is likely to be beneficial beyond remanufacturing [28].

- Design for Remanufacturing implementation is most effective when considered at an early stage of the product development process $[24,28,35,53,61]$.

- By considering remanufacturing during the product planning process, improved levels of implementation of Design for Remanufacturing can be achieved [39].

- The amount of investment available to implement Design for Remanufacturing may be dependent of the company's size [29].

- Calculations for the amount of required spare parts needs to be adjusted when products are being remanufactured; this should take place at the early stage product development [49].

- Subjectivity in existing Design for Remanufacturing guidelines should be reduced to a minimum [29].

- Ways to adjust Design for Remanufacturing guidelines to fit a specific product should be addressed [29].

- Most design tools from literature are complex and mainly support later stages of product development [28].

- Links with, and the use of, existing design tools is beneficial because of familiarity in industry [28].

- Instructions as to how Design for Remanufacturing design tools should be integrated in existing processes is missing [28].

- Many tools as presented in literature are too complex and technical to apply in early stage product development [28].

- Guidelines for Design for Remanufacturing are present in literature, yet in low volume [28].

- Proof needs to be collected about the effectivity for businesses of existing Design for Remanufacturing [28].

- Design for Remanufacturing tools do not meet the need of the users of the tools (e.g. high complexity or time consuming) [28].

- The uptake of Design for Remanufacturing tools is expected to improve along with the product engineers' awareness of remanufacturing operations [29].

- Implementing Design for Remanufacturing can only take place effectively with the right tools and under the condition that those implementing it have acquired deep knowledge of the subject [61].

Design as transformer

(Learning perspective)

Opportunities and barriers

Innovation

- With the production of durable products, or products lasting multiple lifetimes, the turnover rate of the product stock decreases and therewith slows down the possibility of introducing new innovations, which may have an effect on market demand and the implementation of sustainable innovations [42, 49].

- New market introductions in some cases rely solely on renewed aesthetics to boost sales, independent of improvement in functionality [42].

- New market introductions are often characterized by having both improved aesthetics and functionality [42].

- Time-to-market lead time can be decreased significantly by remanufacture $[45,49]$.

- Without interfering with product innovation, standardization of components should be maximized [42].

Business development

- Access models, performance models, or other product-service systems, are business models enabling higher volumes of retuning products for remanufacturing $[35,55,56]$.

- Design for Remanufacturing can be used to make the business approach of remanufacturing more efficient [28]. 
Table 4 (continued)

- Setting up new collaborations and partnerships within the supply chain can improve the efficiency of remanufacturing activities $[35,53]$.

Design as good business

(Financial perspective)

Opportunities and barriers

Financial drivers

- Good alignment between a product's design and the remanufacturing process improved efficiency and, with that, profit margins $[9,29,41]$.

- Remanufacturing activities contribute to the environmental goals of companies [29].

- The effects of providing warranties for remanufactured products are unclear (e.g. increased servicing costs) [51].

- A more expensive design may increase short-term costs [42].

- Labour costs for remanufacturing are high [51].

- By combining the purchase of testing equipment for both manufacturing and remanufacturing, cost savings can be achieved [53].

- The more integrated a remanufacturing strategy is, the higher the ecological benefits, and the more likely it is to receive (future) tax credits or governmental support [53].

- A key driving force for remanufacturing is a high initial production cost in combination with low costs to remanufacture [17]

Market share

- Competitors with remanufacturing activities may also activate OEMs to start up remanufacturing [29].

- The entry of non-contracted third-party remanufacturers into the market forms a risk for OEMs [48].

- Low-budget entries, or competition from emerging economies, can form a threat to remanufacturing businesses $[35,53]$.

- OEM remanufacturing can keep third party remanufacturers out of the market [53].

- The possibility of cannibalization of new product sales is seen as a threat [35].

External drivers

- Environmental regulations demanding higher levels of Extended Producer Responsibility (ERP) posed by governments are likely to become more stringent over time [53].

\section{Appendix 2}

\section{Company descriptions:}

Air treatment units for buildings - This company offers customised solutions for air treatment systems for buildings. The products have high potential to be remanufactured as they are built up out of standardised parts, with varying dimensions. The design is highly modular, upgradable and made of long-lasting materials. The product technology is relatively stable, and functionality and costs are the main selling points

Outdoor furniture - This company develops products for the public domain. Examples of such products are street furniture, bike parks, infrastructural devices, and equipment for sports and play grounds. The products are made from highly durable, wear-resistant materials, from both a functional and aesthetical point of view. The products are designed according to the specifications in a tender

Vessel and maritime equipment - This company offers a range of products used in the maritime industry. These large systems typically have extremely long lifetimes, lasting for many decades. Activities for the application of these systems range from dredging, oil and gas, offshore wet mining, etc. Large amounts of high-grade materials are used requiring enormous investments 
Window shades - This company develops and manufactures high-end, bespoke shading products for facades of buildings. The products are made from durable and well-recyclable materials, and the design allows for ease of disassembly and replacement of parts. Main selling points of the products are the aesthetics, the functionality, and costs

Electro motors - This company offers customised electro motors for a broad range of applications, from all sorts of conveyers to industrial mixers, grinders and cranes. The lay-out of the production process for new products is set up in a way that it allows for integration of remanufacturing in the same process. Existing customers can make use of this to remanufacture their products, which offers benefits like maintaining exactly the same product specification, as well as cost-saving

Professional coffee machines - This company retains ownership of their products and offers access or performance models to customers. The machines are installed the preferred location and offers are based on either a monthly fee (access model) or a price per served beverage (performance model). The machines are designed for service and maintenance and therefore enable ease of replacement of parts and ease of recovery to return the product to its original state

Electro motors - Using their knowledge of producing new electro motors, this company remanufactures used electro motors as a contractor. The company has a dedicated production line for high-grade recovery of each of the parts of this product, allowing their customers to make efficient use of their resources. Since the company has gained experience in, and developed a method for, remanufacturing, they are also expanding to other product groups

\section{Appendix 3}

\section{Interview protocol:}

- Can you describe your current offer?

- What product functionality do you offer?

- To what target market?

- To meet what market needs?

- Do you offer performance related services (e.g. maintenance, quality control)?

- Do you offer any additional services?

- In what way is the value proposition for remanufactured products different from newly produced products? Or in what way would it be different?

- What are barriers to remanufacture your product?

- What are drivers to remanufacture your product?

- What are enablers to remanufacture your product?

- What type of investments are required for remanufacturing? If applicable

- How are your products developed?

- What process steps do you follow?

- Which departments/ functions outside of the product development department contribute to product development? And why?

- Do you Design for Remanufacturing? In what way? 
- How do you deal with (future) technological developments during product design (in relation to remanufacturing)?

- Do you make use of critical materials?

- What does your remanufacturing process look like? If applicable

- What are the most time-consuming steps? And why?

- What are the costliest steps? And why?

- Do you improve the product during the process?

- Are you planning to implement new business models, like service-based business models?

- Would this be desirable?

- Can you give an example?

- Who would be involved in this process?

- What prevents this from happening now?

- What additional services could you offer your clients through remanufacturing?

- Would this be desirable?

- Can you give an example?

- Who would be involved in this process?

- What prevents this from happening now?

- How do you market your remanufactured products? (/ How do you ensure customer acceptance?) If applicable

- Do you target the same customer segment for remanufactured products as for new products?

- Through which channels?

Open Access This article is licensed under a Creative Commons Attribution 4.0 International License, which permits use, sharing, adaptation, distribution and reproduction in any medium or format, as long as you give appropriate credit to the original author(s) and the source, provide a link to the Creative Commons licence, and indicate if changes were made. The images or other third party material in this article are included in the article's Creative Commons licence, unless indicated otherwise in a credit line to the material. If material is not included in the article's Creative Commons licence and your intended use is not permitted by statutory regulation or exceeds the permitted use, you will need to obtain permission directly from the copyright holder. To view a copy of this licence, visit http://creativecommons.org/licenses/by/4.0/.

\section{References}

1. Abbey JD, Kleber R, Souza GC, Voigt G (2017) The role of perceived quality risk in pricing remanufactured products. Prod Oper Manag 26(1):100-115. https://doi.org/10.1111/poms.12628

2. Acceptance (n.d.) In Cambridge Dictionary. Retrieved from https://dictionary.cambridge. org/dictionary/english/acceptance 
3. Amezquita, T., Hammond, R., Salazar, M., \& Bras, B. (1995, September). Characterizing the remanufacturability of engineering systems. In ASME Advances in Design Automation Conference (Vol. 82, pp. 271-278)

4. Bakker, C., den Hollander, M., Van Hinte, E., \& Zijlstra, Y. (2014). Products that last: product design for circular business models. TU Delft Library

5. Boorsma, N., Tsui, T., \& Peck, D. (2019) Circular building products, a case study of soft barriers in design for remanufacturing. In Proceedings of the International conference of Remanufacturing 2019

6. Borja de Mozota B (2002) Design and competitive edge: a model for design management excellence in European SMEs. Des Manag J 2:88-103

7. Borja de Mozota B (2006) The four powers of design: a value model in design management. Design Management Review 17(2):44-53

8. Business (n.d.) In Cambridge Dictionary. Retrieved from https://dictionary.cambridge. org/dictionary/english/business

9. Bras, B., \& Hammond, R. (1996, November). Towards Design for Remanufacturing-metrics for assessing remanufacturability. In Proceedings of the 1st International Workshop on Reuse, 5-22

10. Calabretta G, Gemser G (2017) Building blocks for effective strategic design. Journal of Design, Business \& Society 3(2):109-124. https://doi.org/10.1386/dbs.3.2.109_1

11. Collaboration (n.d.) In Cambridge Dictionary. Retrieved from https://dictionary.cambridge. org/dictionary/english/collaboration

12. Commitment (n.d.) In Cambridge Dictionary. Retrieved from https://dictionary.cambridge. org/dictionary/english/commitment

13. Cooper, R.; Junginger, S.; Lockwood, T. (Eds.) (2011). The Handbook of Design Management

14. Cooper R, Press M (1995) The design agenda: a guide to successful design management. John Wiley and Sons

15. Customer relationship (n.d.) In Cambridge Dictionary. Retrieved from https://dictionary.cambridge. org/dictionary/english/customer-relationship

16. Daugherty PJ, Richey RG, Hudgens BJ, Autry CW (2003) Reverse logistics in the automobile aftermarket industry. Int J Logist Manag 14(1):49-62

17. Debo LG, Toktay LB, Van Wassenhove LN (2005) Market segmentation and product technology selection for remanufacturable products. Manag Sci 51(8):1193-1205. https://doi.org/10.1287/mnsc.1050.0369

18. Development (n.d.) In Cambridge Dictionary. Retrieved from https://dictionary.cambridge. org/dictionary/english/development

19. Driver (n.d.) In Cambridge Dictionary. Retrieved from https://dictionary.cambridge. org/dictionary/english/driver

20. External (n.d.) In Cambridge Dictionary. Retrieved from https://dictionary.cambridge. org/dictionary/english/external

21. Esmaeilian B, Behdad S, Wang B (2016) The evolution and future of manufacturing: a review. J Manuf Syst 39:79-100. https://doi.org/10.1016/j.jmsy.2016.03.001

22. European Commission (EC) (2015). COM 614 final - Communication from the Commission to the European Parliament, the Council, the European Economic and Social Committee and the Committee of the Regions. Retrieved from: https:/eur-lex.europa.eu/legal-content/EN/TXT/?uri=CELEX\%3A52015 DC0614

23. Financial (n.d.) In Cambridge Dictionary. Retrieved from https://dictionary.cambridge. org/dictionary/english/financial

24. Gehin A, Zwolinski P, Brissaud D (2008) A tool to implement sustainable end-of-life strategies in the product development phase. J Clean Prod 16(5):566-576. https://doi.org/10.1016/j.jclepro.2007.02.012

25. Govindan K, Jiménez-Parra B, Rubio S, Vicente-Molina MA (2019) Marketing issues for remanufactured products. J Clean Prod 227:890-899. https://doi.org/10.1016/j.jclepro.2019.03.305

26. Gray C, Charter M (2008) Remanufacturing and product design. Int J Prod Dev 6(3-4):375-392

27. Guide VDR Jr (2000) Production planning and control for remanufacturing: industry practice and research needs. J Oper Manag 18(4):467-483. https://doi.org/10.1016/S0272-6963(00)00034-6

28. Hatcher GD, Ijomah WL, Windmill JFC (2011) Design for remanufacture: a literature review and future research needs. J Clean Prod 19(17-18):2004-2014. https://doi.org/10.1016/j.jclepro.2011.06.019

29. Hatcher GD, Ijomah WL, Windmill JFC (2013) Integrating design for remanufacture into the design process: the operational factors. J Clean Prod 39:200-208. https://doi.org/10.1016/j.jclepro.2012.08.015

30. Hazen BT, Boone CA, Wang Y, Khor KS (2017) Perceived quality of remanufactured products: construct and measure development. J Clean Prod 142:716-726. https://doi.org/10.1016/j.jclepro.2016.05.099

31. Ijomah WL, McMahon CA, Hammond GP, Newman ST (2007) Development of robust design-forremanufacturing guidelines to further the aims of sustainable development. Int J Prod Res 45(18-19): 4513-4536 
32. IRP (2018) Re-defining Value - The Manufacturing Revolution. Remanufacturing, Refurbishment, Repair and Direct Reuse in the Circular Economy. Nabil Nasr, Jennifer Russell, Stefan Bringezu, Stefanie Hellweg, Brian Hilton, Cory Kreiss, and Nadia von Gries. A Report of the International Resource Panel. United Nations Environment Programme, Nairobi, Kenya. Retrieved from: https://www.resourcepanel. org/reports/re-defining-value-manufacturing-revolution

33. Information management (n.d.) In Cambridge Dictionary. Retrieved from https://dictionary.cambridge. org/dictionary/english/information-management

34. Integration (n.d.) In Cambridge Dictionary. Retrieved from https://dictionary.cambridge. org/dictionary/english/integration

35. Karvonen I, Jansson K, Behm K, Vatanen S, Parker D (2017) Identifying recommendations to promote remanufacturing in Europe. Journal of Remanufacturing 7(2-3):159-179. https://doi.org/10.1007/s13243017-0038-2

36. Kerr W, Ryan C (2001) Eco-efficiency gains from remanufacturing: a case study of photocopier remanufacturing at Fuji Xerox Australia. J Clean Prod 9(1):75-81. https://doi.org/10.1016/S0959-6526 (00)00032-9

37. Lange, U. (2017) Resource efficiency through remanufacturing. VDI Zentrum Ressourceneffizienz GmbH. Retrieved from: https://www.resource-germany.com/fileadmin/user_upload/downloads/kurzanalysen/VDI_ ZRE_KA18_Remanufacturing_en_bf.pdf

38. Law J (2009) A dictionary of business and management, 5th edn. Oxford University Press, URL https://www.oxfordreference.com/view/10.1093/acref/9780199234899.001.0001/acref-9780199234899

39. Lindkvist Haziri L, Sundin E (2019) Supporting Design for Remanufacturing-a framework for implementing information feedback from remanufacturing to product design. Journal of Remanufacturing 10:1-20. https://doi.org/10.1007/s13243-019-00077-4

40. Lindkvist Haziri L, Sundin E, Sakao T (2019) Feedback from remanufacturing: its unexploited potential to improve future product design. Sustainability 11(15):4037. https://doi.org/10.3390/su11154037

41. Linton JD (2008) Assessing the economic rationality of remanufacturing products. J Prod Innov Manag 25(3):287-302. https://doi.org/10.1111/j.1540-5885.2008.00301.x

42. Lund RT, Denney WM (1977) Opportunities and implications of extending product life. Center for Policy Alternatives, Massachusetts Institute of Technology

43. Lund RT, Mundial B (1984) Remanufacturing: the experience of the United States and implications for developing countries, vol 31. World Bank, Washington, DC

44. Market share (n.d.) In Merriam-Webster.com. Retrieved from https://www.merriam-webster. com/dictionary/market\%20share

45. Matsumoto M, Chinen K, Endo H (2018) Remanufactured auto parts market in Japan: historical review and factors affecting green purchasing behavior. J Clean Prod 172:4494 4505. https://doi.org/10.1016/j. jclepro.2017.10.266

46. Matsumoto M, Yang S, Martinsen K, Kainuma Y (2016) Trends and research challenges in remanufacturing. International Journal of Precision Engineering and Manufacturing-Green Technology 3(1):129-142. https://doi.org/10.1007/s40684-016-0016-4

47. Milios L, Matsumoto M (2019) Consumer perception of remanufactured automotive parts and policy implications for transitioning to a circular economy in Sweden. Sustainability 11(22):6264. https://doi. org/10.3390/su11226264

48. Michaud C, Llerena D (2011) Green consumer behaviour: an experimental analysis of willingness to pay for remanufactured products. Bus Strateg Environ 20(6):408-420. https://doi.org/10.1002/bse.703

49. Parker, D., Riley, K., Robinson, S., Symington, H., Tewson, J., Jansson, K., Ramkumar, S. \& Peck, D. (2015). Remanufacturing market study

50. Pigosso DC, Zanette ET, Guelere Filho A, Ometto AR, Rozenfeld H (2010) Ecodesign methods focused on remanufacturing. J Clean Prod 18(1):21-31. https://doi.org/10.1016/j.jclepro.2009.09.005

51. Prendeville S, Bocken N (2017) Design for remanufacturing and circular business models, In Sustainability through innovation in product life cycle design (pp. 269-283). Springer, Singapore. https://doi.org/10.1007 /978-981-10-0471-1_18

52. Rashid A, Asif FM, Krajnik P, Nicolescu CM (2013) Resource conservative manufacturing: an essential change in business and technology paradigm for sustainable manufacturing. J Clean Prod 57:166-177. https://doi.org/10.1016/j.jclepro.2013.06.012

53. Subramoniam R, Huisingh D, Chinnam RB (2010) Aftermarket remanufacturing strategic planning decision-making framework: theory \& practice. J Clean Prod 18(16-17):1575-1586. https://doi. org/10.1016/j.jclepro.2010.07.022

54. Sundin E. (2002) Design for Remanufacturing from a remanufacturing process perspective, Linköping studies in science and technology, licentiate thesis no. 944, LiU-TEK-LIC-2002-17, Department of Mechanical Engineering, Linköping University, SE-581 83 Linköping, Sweden 
55. Sundin E, Bras B (2005) Making functional sales environmentally and economically beneficial through product remanufacturing. J Clean Prod 13(9):913-925. https://doi.org/10.1016/j.jclepro.2004.04.006

56. Sundin E, Lindahl M, Ijomah W (2009) Product design for product/service systems: design experiences from Swedish industry. J Manuf Technol Manag 20(5):723-753. https://doi.org/10.1108 /17410380910961073

57. Support (n.d.) In Cambridge Dictionary. Retrieved from https://dictionary.cambridge. org/dictionary/english/support

58. Wang, Y., Wiegerinck, V., Krikke, H., \& Zhang, H. (2013). Understanding the purchase intention towards remanufactured product in closed-loop supply chains. International Journal of Physical Distribution \& Logistics Management

59. Watson, M. (2008). A review of literature and research on public attitudes, perceptions and behaviour relating to remanufactured, repaired and reused products. Report for the Centre for Remanufacturing and Reuse, 1-26

60. Yin RK (2018) Case study research and applications: design and methods. Sage publications

61. Zwolinski P, Lopez-Ontiveros MA, Brissaud D (2006) Integrated design of remanufacturable products based on product profiles. J Clean Prod 14(15-16):1333-1345. https://doi.org/10.1016/j. jclepro.2005.11.028

Publisher's note Springer Nature remains neutral with regard to jurisdictional claims in published maps and institutional affiliations.

\section{Affiliations}

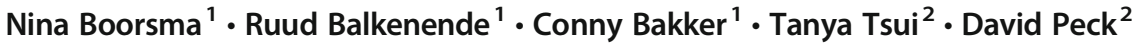

Ruud Balkenende

A.R.Balkenende@tudelft.nl

Conny Bakker

C.A.Bakker@tudelft.nl

Tanya Tsui

T.P.Y.Tsui@tudelft.nl

David Peck

D.P.Peck@tudelft.nl

1 Faculty of Industrial Design Engineering, Delft University of Technology, Landbergstraat 15, 2826 CE Delft, the Netherlands

2 Faculty of Architecture and the Built Environment, Delft University of Technology, Julianalaan 134, 2628 BL Delft, the Netherlands 